\title{
Anti-parasitic Drug Ivermectin Exhibits Potent Anticancer Activity Against Gemcitabine-resistant Cholangiocarcinoma In Vitro
}

\author{
KITTI INTUYOD ${ }^{1,2}$, CHARIYA HAHNVAJANAWONG ${ }^{3}$, PORNTIP PINLAOR ${ }^{2,4}$ and SOMCHAI PINLAOR ${ }^{1,2}$ \\ ${ }^{1}$ Department of Parasitology, Faculty of Medicine, Khon Kaen University, Khon Kaen, Thailand; \\ ${ }^{2}$ Cholangiocarcinoma Research Institute, Faculty of Medicine, Khon Kaen University, Khon Kaen, Thailand; \\ ${ }^{3}$ Department of Microbiology, Faculty of Medicine, Khon Kaen University, Khon Kaen, Thailand; \\ ${ }^{4}$ Centre for Research and Development in Medical Diagnostic Laboratory, \\ Faculty of Associated Medical Sciences, Khon Kaen University, Khon Kaen, Thailand
}

\begin{abstract}
Background/aim: The antiparasitic drug, ivermectin (IVM), exerts anticancer activities in diverse cancer types. However, its anticancer activity against cholangiocarcinoma (CCA), especially the drug-resistant phenotype, has not yet been explored. Materials and Methods: IVM was tested for its anticancer activity against gemcitabine-sensitive (KKU214) and gemcitabine-resistant (KKU214 $4^{\mathrm{GemR}}$ ) CCA cell lines in vitro using the sulforhodamine $B$ and clonogenic assays as well as cellcycle analysis. Results: IVM treatment inhibited cell proliferation and colony formation of both KKU214 and $K K U 214^{\mathrm{GemR}}$ in a dose- and time-dependent manner. $K K U 214^{\mathrm{GemR}}$ cells were more sensitive than KKU214 to IVM treatment. IVM treatment caused S-phase cell-cycle arrest and also cell death as indicated by an increase of sub$G_{0} / G_{1}$ population in KKU214 $\mathrm{GemR}$ cells treated with IVM for 48 h. Conclusion: IVM exerts anti-CCA activities and gemcitabine-resistant KKU214 ${ }^{\mathrm{GemR}}$ cells are more sensitive to IVM treatment. Thus, IVM might be useful as an alternative treatment for CCA, especially in patients who do not respond to gemcitabine.
\end{abstract}

Chemotherapeutic drugs have been developed and used as first-line treatment of several cancers. Although satisfactory outcomes are usually achieved at the beginning of treatment, the efficacy any drug tends to decline over time. Cancer cells

Correspondence to: Prof. Somchai Pinlaor, Ph.D., Department of Parasitology, Faculty of Medicine, Khon Kaen University, Khon Kaen 40002, Thailand. Tel: +66 43348387, Fax: +66 43 202475, e-mail: psomec@kku.ac.th

Key Words: Ivermectin, cholangiocarcinoma, drug resistance, gemcitabine, KKU214GemR. can adapt to the toxic effects of chemotherapy and eventually become tolerant of the drug $(1,2)$. Drug resistance is the major impediment to effective cancer therapy and has been observed in several cancers including cholangiocarcinoma (CCA), a bile-duct cancer originating from bile-duct epithelial cells. Although surgical resection can be effective for CCA treatment, approximately two-thirds of CCA patients are inoperable (3). Hence, chemotherapy is a treatment of choice and has been used to control disease progression and improve survival and quality of life for unresectable CCA patients (4). Gemcitabine (2', 2'difluorodeoxycytidine) is a deoxycytidine analogue which has been widely used for treatment of CCA (3). However, several clinical studies have indicated that response rates and overall survival rates are relatively low (4), likely due to acquired drug resistance. Therefore, it is necessary to identify other agents or drugs that can be used against drugresistant CCA.

Ivermectin (IVM) is a derivative of avermectin and was discovered in 1970. IVM is one of the most effective antiparasitic drugs and is widely used in human and veterinary medicine (5). Apart from its anti-parasitic activity, IVM has been shown to exert anti-cancer activities including inhibition of proliferation as well as induction of apoptosis and autophagy (6-8). The anticancer activities of IVM have been observed both in vitro and in vivo in a number of solid tumors such as colon cancer (9), glioblastoma (10), ovarian cancer (11) and in hematological malignancies such as leukemia (12). IVM has also been shown to reverse the drug resistance of cancer cells (13-15). Therefore, IVM is a promising anticancer agent and could possibly be used against drug-resistant cancers.

It is not known whether IVM can exert anticancer activity against CCA, and especially against drug-resistant CCA. Herein, we explored the anti-CCA activity of IVM and 
A

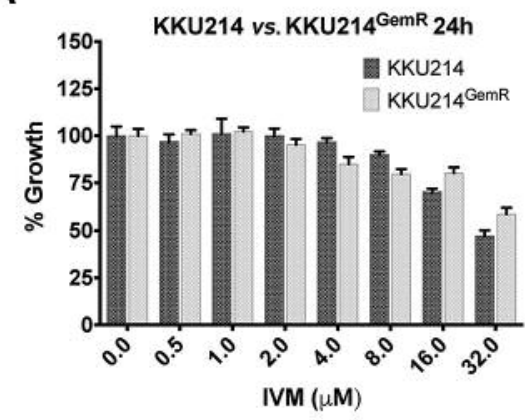

B

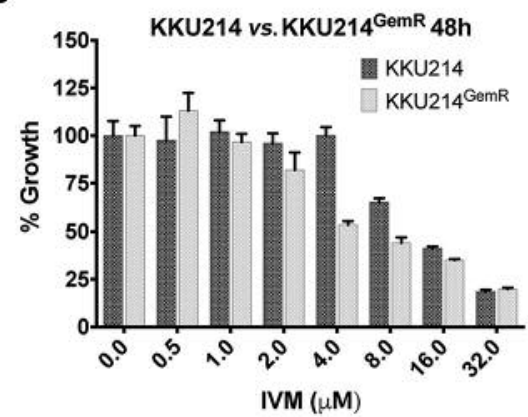

C

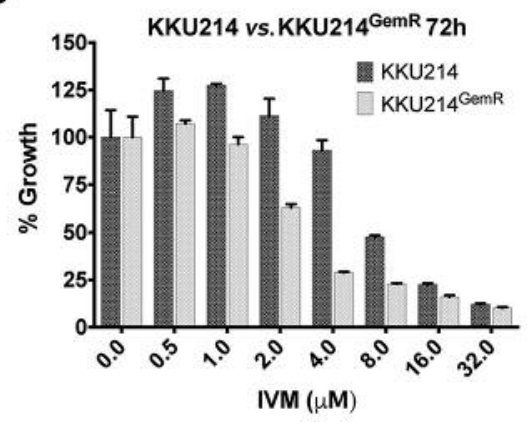

Figure 1. IVM treatment inhibited cell proliferation of KKU214 and KKU214GemR CCA cell lines. The anti-proliferative activity of IVM was evaluated using the SRB assay. Both KKU214 and KKU214GemR CCA cell lines were treated with different concentrations of IVM for (A) 24 h, (B) $48 \mathrm{~h}$ and $(C) 72 \mathrm{~h}$. DMSO-treated cells were used as controls. The experiment was performed in triplicate. IVM: Ivermectin.

demonstrated that IVM inhibits CCA cell growth and clonogenicity in dose- and time-dependent manner in both gemcitabine-sensitive and gemcitabine-resistant CCA cell lines in vitro. Interestingly, the anticancer properties of IVM were more prominent in gemcitabine-resistant CCA cells. These results suggest that IVM is a promising agent for treatment of CCA.

\section{Materials and Methods}

Materials. Dulbecco's Modified Eagle's Medium (DMEM), sterile phosphate-buffered saline (PBS), fetal bovine serum (FBS) and penicillin-streptomycin were purchased from Gibco (Grand Island, NY, USA). Trypsin-EDTA solution and flat-bottomed 96-well plates were obtained from Corning (Corning, NY, USA). FxCycle $\mathrm{PI} / \mathrm{RNase}$ staining solution was obtained from Invitrogen (Thermo Fisher Scientific Inc., Waltham, MA, USA). Ivermectin (IVM), dimethyl sulfoxide (DMSO), trichloroacetic acid (TCA) and sulforhodamine B (SRB) were purchased from Sigma Aldrich (St. Louis, MO, USA). Gemcitabine (Gemzar) was purchased from Eli Lilly (Indianapolis, IN, USA).

Human CCA cell lines. Gemcitabine-sensitive CCA KKU214 (16) and gemcitabine-resistant KKU214 (KKU214GemR) cell lines (17) were established from Thai CCA patients as described previously. Both cell lines were maintained in DMEM supplemented with $10 \% \mathrm{FBS}, 100 \mathrm{U} / \mathrm{ml}$ penicillin and $100 \mu \mathrm{g} / \mathrm{ml}$ streptomycin at $37^{\circ} \mathrm{C}$ with $10 \% \mathrm{CO}_{2}$ in a humidified incubator. KKU214GemR was maintained in the presence of gemcitabine. Before use in an experiment, this cell line was cultured in a drug-free medium for one passage.

Assessment of cell proliferation. CCA cells seeded in flat-bottomed 96-well plates $(2,000$ cells/well) were treated with either DMSO (control) or different concentrations of IVM dissolved in DMSO for 24, 48 and $72 \mathrm{~h}$. Thereafter, the cells were fixed with cold $40 \%$ TCA for $1 \mathrm{~h}$ in a refrigerator and washed 3 times with running tap water. Then, the fixed cells were stained with $0.4 \%(\mathrm{w} / \mathrm{v}) \mathrm{SRB}$ solution in $1 \%$ acetic acid for $1 \mathrm{~h}$ at room temperature. Excess SRB solution was removed by washing with $1 \%$ acetic acid and SRB dye was dissolved with $10 \mathrm{mM}$ Tris buffer $\mathrm{pH}$ 10.5. Absorbance at $492 \mathrm{nM}$ was measured using an ELISA reader (Tecan group ltd., Männedorf, Switzerland). Absorbance obtained from DMSO-treated cells was used as control.

Clonogenic assay. Approximately 1,000 cells per well of CCA cell lines were grown in 6-well plates and treated with different concentrations of either gemcitabine or IVM. The culture medium was changed every 2 days and cells were grown for approximately 2 weeks. The cells were then fixed with $4 \%$ paraformaldehyde, stained with $0.5 \%$ crystal violet and dissolved with $33 \%$ acetic acid. The absorbance at $620 \mathrm{nM}$ was measured using an ELISA reader (Tecan group ltd.).

Cell cycle analysis. One million CCA cells treated with either DMSO (control) or $4 \mu \mathrm{M}$ IVM for $48 \mathrm{~h}$ were washed with ice-cold PBS and fixed with $70 \%$ ethanol overnight at $-20^{\circ} \mathrm{C}$. After washing twice with ice-cold PBS, $500 \mu \mathrm{l}$ of FxCycle PI/RNase staining solution were added and the cells were incubated at room temperature in the dark for $30 \mathrm{~min}$. Finally, stained cells were detected using a BD FACSCanto II flow cytometer (BD biosciences, San Jose, CA, USA) and data analyzed using BD FACSDiva software (BD biosciences).

Statistical analysis. Data are expressed as mean \pm SD. Student's $t$-test was used to test differences between experimental groups. A value of $p<0.05$ was considered statistically significant. Non-linear regression analysis was carried out to calculate $\mathrm{IC}_{50}$. All statistical analyses were performed using Graphpad Prism 7.0 for Mac (GraphPad Software, Inc., CA, USA).

\section{Results}

IVM treatment suppressed proliferation of CCA cells and displayed potent growth inhibitory activity against gemcitabine-resistant CCA cells. Both gemcitabinesensitive (KKU214) and gemcitabine-resistant (KKU214 ${ }^{\mathrm{GemR}}$ ) CCA cell lines (17) were treated with different concentrations of IVM for up to $72 \mathrm{~h}$. The SRB assay showed that cell proliferation in both cell lines 
A

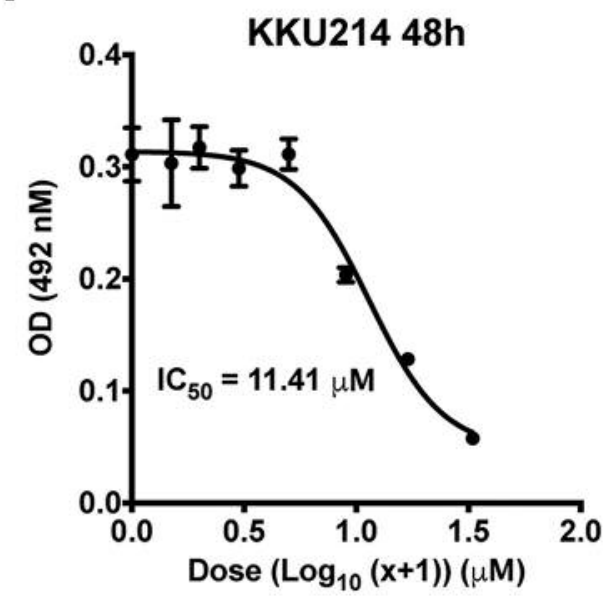

C

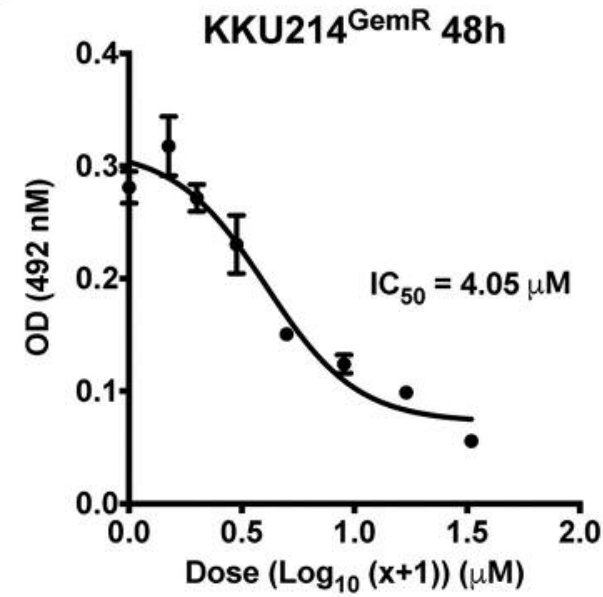

B

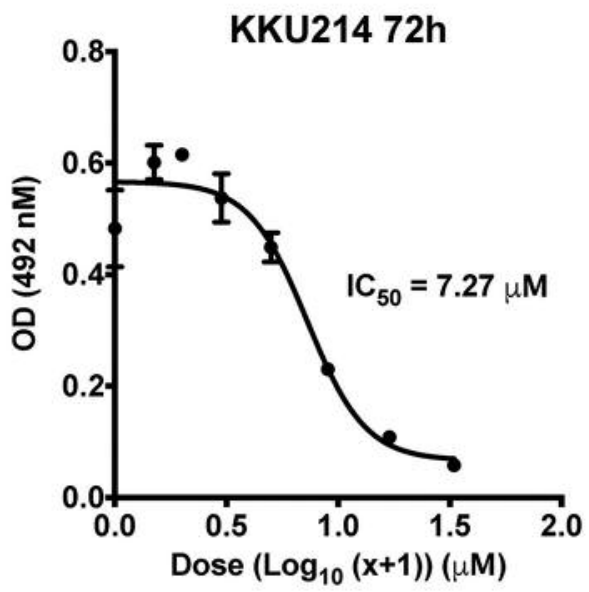

D

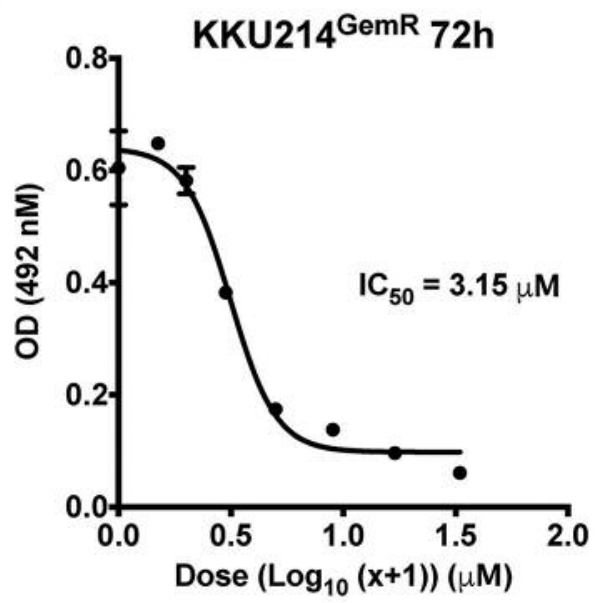

Figure 2. Gemcitabine-resistant KKU214GemR cells were more sensitive to IVM treatment than gemcitabine-sensitive KKU214. Non-linear regression analysis was performed to calculate the half-maximal inhibitory concentration $50\left(I_{50}\right)$ of IVM at $48 \mathrm{~h}$ and $72 \mathrm{~h}$ for $(A, B) \mathrm{KKU} 214$ and $(C, D)$ KKU214GemR CCA cell lines. Data generated from the SRB assay were used for calculation.

decreased in dose- and time-dependent manner (Figure 1). Potent cell proliferation inhibition (more than $75 \%$ ) was achieved in both CCA cell lines treated with $32 \mu \mathrm{M}$ of IVM for $48 \mathrm{~h}$ or $72 \mathrm{~h}$ (Figure 1B and C). Interestingly, KKU214 GemR cells, which are extremely resistant to gemcitabine, were more sensitive to IVM treatment than the parental KKU214 cell line. This was particularly apparent at concentrations of IVM of $4 \mu \mathrm{M}$ or higher, at all time points. Non-linear regression analysis showed that the $\mathrm{IC}_{50}$ concentrations of IVM at $48 \mathrm{~h}$ and $72 \mathrm{~h}$ for KKU214 cells were $11.41 \mu \mathrm{M}$ and $7.27 \mu \mathrm{M}$, respectively. Corresponding values for KKU214 ${ }^{\mathrm{GemR}}$ cells were $4.05 \mu \mathrm{M}$ and $3.15 \mu \mathrm{M}$, respectively (Figure 2). These findings indicated that IVM exhibited anti-CCA potential, especially for gemcitabine-resistant CCA cells.
IVM treatment inhibited clonogenicity of CCA cells. A clonogenic assay was employed to test the ability of IVM to inhibit unlimited division and colony formation of CCA cell lines (18). In line with the SRB assay, IVM treatment significantly inhibited colony formation of KKU214 cells in a dose-dependent manner compared to untreated controls $(p<0.0001)$, but was less effective than a similar dosage of gemcitabine (Figure 3A-C). In contrast, gemcitabine treatment was ineffective against the KKU214 ${ }^{\mathrm{GemR}} \mathrm{CCA}$ cell line (Figure 3A and D), whereas IVM treatment significantly suppressed colony formation of KKU214 GemR cells compared to untreated controls ( $p<0.0001$, Figure $3 \mathrm{~B}$ and D). Once again, the inhibitory effect of IVM on colony formation was more potent in KKU214 ${ }^{\mathrm{GemR}}$ cells compared to KKU214 cells. These results suggest that IVM exerts its 
A

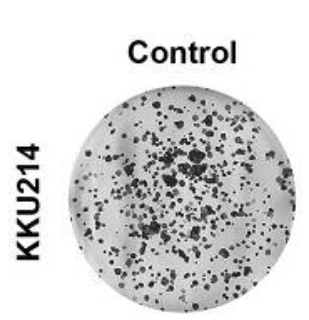

Gemcitabine $5 \mu \mathrm{M}$

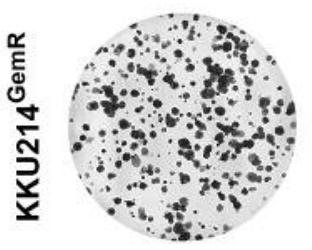

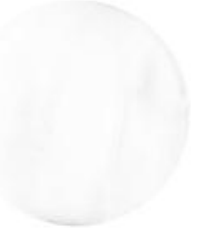

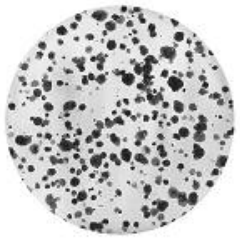

$10 \mu \mathrm{M}$
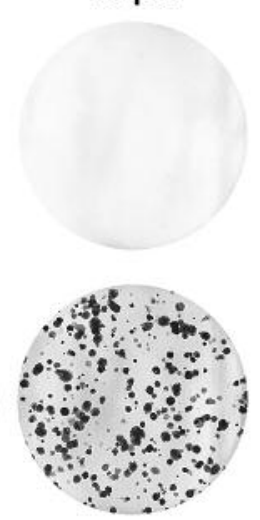

B
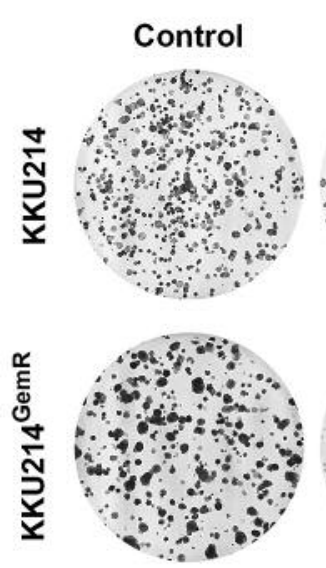

Ivermectin
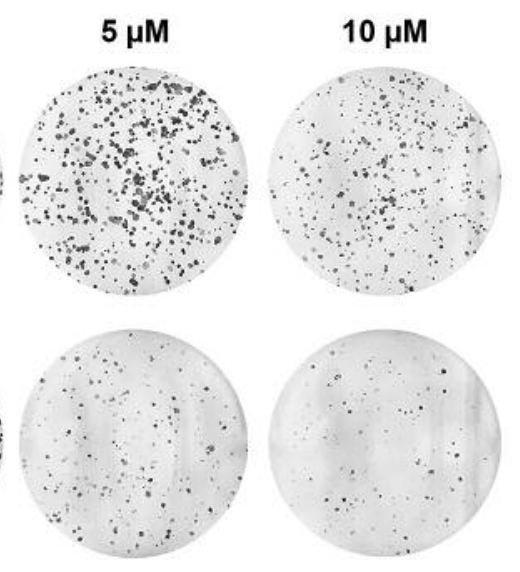

C

D
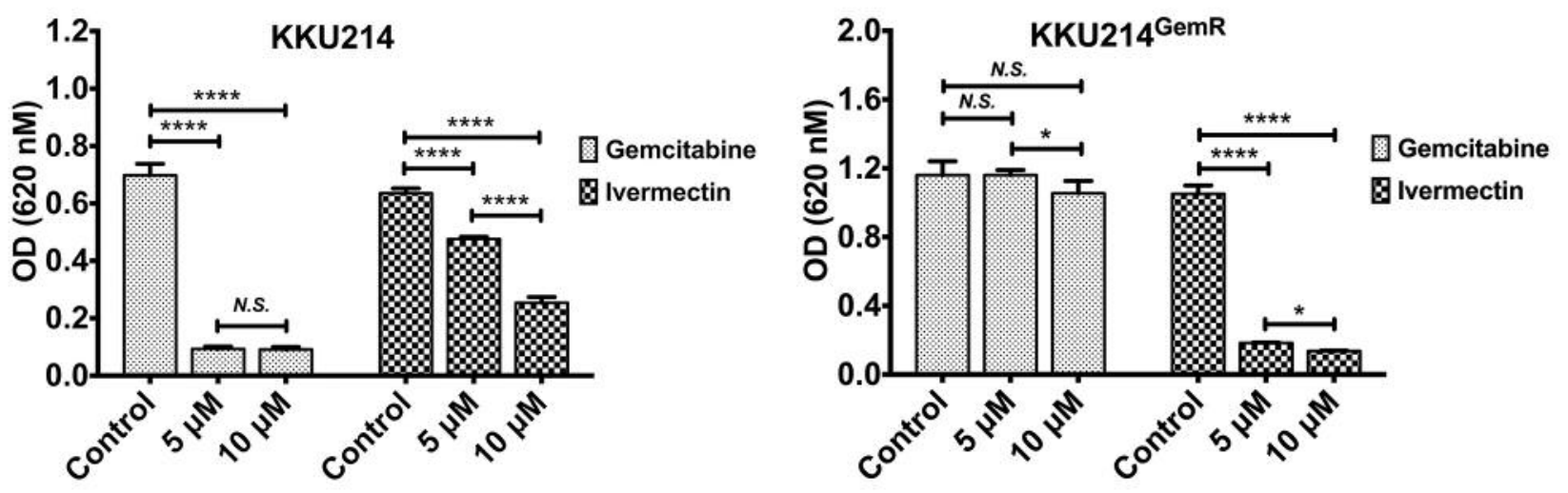

Figure 3. IVM treatment inhibited colony formation of KKU214 and KKU214GemR CCA cell lines. The effect of (A) gemcitabine treatment and (B) IVM treatment on colony formation of both CCA cell lines was investigated using a clonogenic assay. Relative differences in colony formation of (C) KKU214 and (D) KKU214GemR CCA cell lines treated with either gemcitabine or IVM compared to controls was investigated by measuring absorbance at optical density $(O D) 620 \mathrm{nM}$. The experiment was performed in triplicate. $*$ and $* * * *$ indicate a significant difference at p<0.05 and $p<0.0001$, respectively. N.S.: No significant difference.

anti-CCA activity partly through inhibition of unlimited division and colony formation.

IVM treatment induced cell-cycle arrest of gemcitabineresistant KKU214 GemR. Since the SRB assay demonstrated the growth inhibition properties of IVM against CCA cell lines, we then examined whether induction of cell-cycle arrest contributed to this phenomenon. Flow cytometry demonstrated that the cell-cycle profiles of the IVM-treated KKU214 cells did not differ from those of controls (Figure $4 \mathrm{~A}-\mathrm{C})$. However, treatment with $4 \mu \mathrm{M}$ of IVM for $48 \mathrm{~h}$ significantly induced cell-cycle arrest at the $\mathrm{S}$ phase in KKU214 ${ }^{\mathrm{GemR}}$ cells compared to controls $(p<0.01$, Figure $4 D-F)$. Furthermore, the population of sub- $\mathrm{G}_{0} / \mathrm{G}_{1}$ of IVMtreated KKU214 ${ }^{\mathrm{GemR}}$ cells, an indicator of apoptotic cell death (19), was significantly higher compared to controls (2.93 \pm 0.83 vs. $0.67 \pm 0.15, p<0.05$, Figure 4D-F). Therefore, in addition to inhibition of growth and colony formation, IVM treatment can induce apoptotic cell death of KKU214 GemR cells.

\section{Discussion}

Resistance to conventional chemotherapy has been the most important obstacle for effective treatment of many cancer types including CCA. In addition to the increasing chance of relapse, the development of cancer drug resistance could possibly make treatment nearly impossible (20). A number of therapeutic approaches to circumvent this problem have been proposed such as targeted therapy (21), nanomedicine 
A

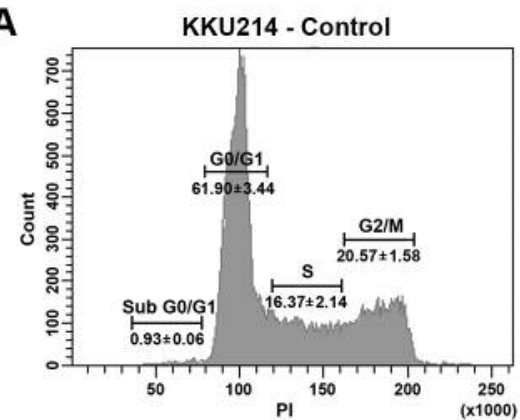

D

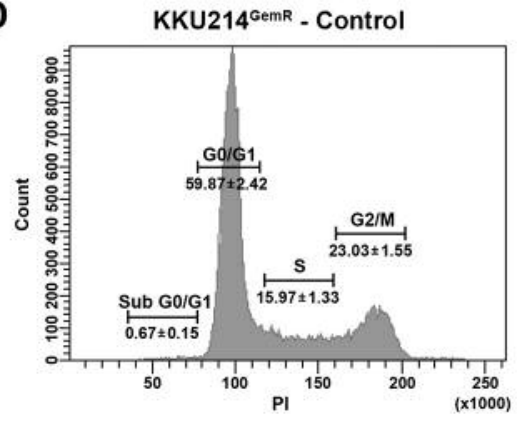

B

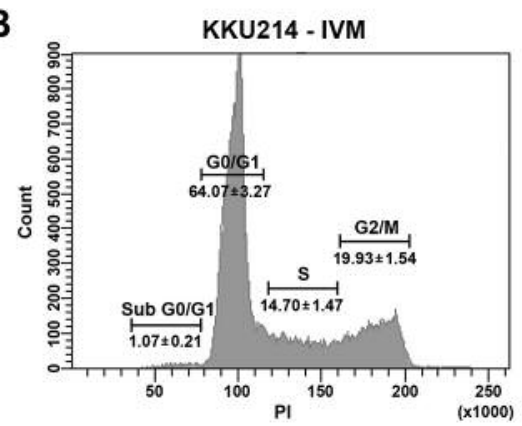

E

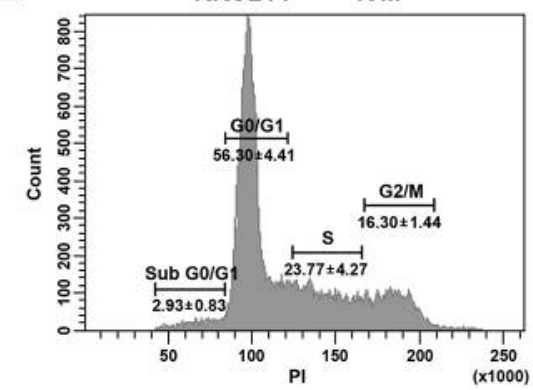

C

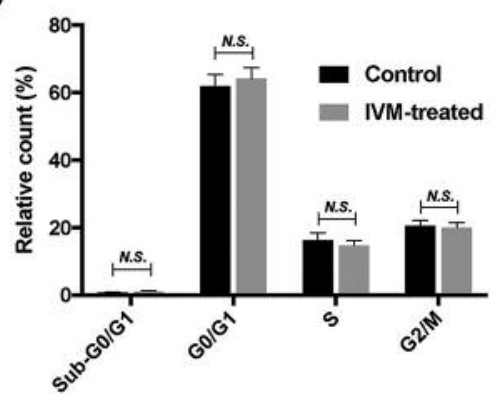

$\mathbf{F}$

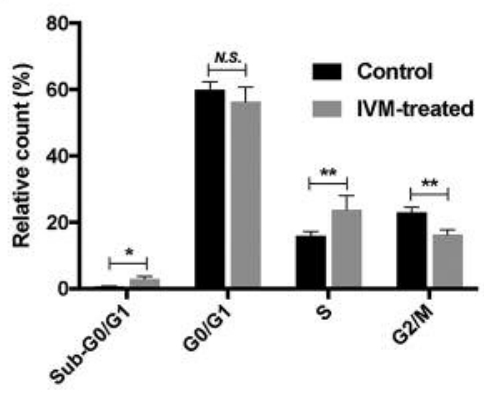

Figure 4. IVM treatment caused S-phase and sub-G $G_{0} G_{1}$ cell-cycle arrest of KKU214GemR. Cell-cycle analysis of (A-C) KKU214 and $(D-F)$ KKU214GemR CCA cell lines after treatment with either DMSO (controls) or $4 \mu M$ of IVM for 48 h, was performed by flow cytometry. Cell-cycle distribution was visualized using BD FACSDiva software. The experiment was performed in triplicate. * and ** indicate a significant difference at $p<0.05$ and $p<0.01$, respectively. N.S.: No significant difference.

(22), drug combination therapy using drugs with different actions (23), etc. However, the efficacy of these approaches for treatment of drug-resistant cancer has been questioned. Herein, we demonstrated that the anti-parasitic drug IVM exerts anticancer activity against CCA cells. Importantly, IVM also exerted a potent anticancer activity against gemcitabine-resistant CCA cells.

Due to its safety and high efficacy, IVM has been used for treating both endo- and ectoparasites of animals and humans for decades (24). IVM is also known to act against several cancer types. A number of mechanisms have been found to be associated with the anticancer activity of IVM. However, an antiproliferative function has been widely reported (8). We found that IVM treatment effectively inhibited cell proliferation and colony formation of both gemcitabinesensitive and gemcitabine resistant CCA cell lines. Our findings are in general agreement with a previous report investigating colon cancer (9). Notably, non-linear regression analysis found that the $\mathrm{IC}_{50}$ of IVM against KKU214 cells was higher than that in KKU214 ${ }^{\mathrm{GemR}}$ cells. Increased expression levels of chloride channels (12), which are usually observed in drug resistant cancer cells (25-27), might be responsible for the difference in susceptibility to IVM between these cell lines. Furthermore, there might be a difference in transcriptomic profile between gemcitabine- sensitive and gemcitabine-resistant CCA cell lines (28). Cellcycle analysis found that IVM treatment induced cell death of KKU214 ${ }^{\mathrm{GemR}}$ cells as demonstrated by the significant increase in the sub- $G_{0} / G_{1}$ population. The induction of death of KKU214 ${ }^{\mathrm{GemR}}$ cells by IVM may be mediated by the induction of mitochondrial dysfunction and oxidative DNA damage as demonstrated in renal cancer cells (29) and glioblastoma (10). However, significant cell-cycle arrest was not observed in the KKU214 CCA cell line treated with $4 \mu \mathrm{M}$ of IVM for $48 \mathrm{~h}$, consistent with the cell proliferation assay in which treatment with $4 \mu \mathrm{M}$ of IVM did not cause a significant decrease in cell-proliferation rate compared to controls. These results indicate that drug resistant cells are more susceptible to IVM-induced cytostasis and cell death. However, the precise mechanism by which IVM exerts anticancer activity against CCA cells, especially drug resistant cancer cells, remains to be elucidated.

\section{Conclusion}

IVM treatment exhibited anti-CCA potential as shown by inhibition of cell growth and colony formation of CCA cell lines. The anticancer activities of IVM were more potent in gemcitabine-resistant KKU214 ${ }^{\mathrm{GemR}}$ cells. Furthermore, IVM treatment also induced $\mathrm{S}$-phase and sub- $\mathrm{G}_{0} / \mathrm{G}_{1}$ cell-cycle 
arrest in gemcitabine-resistant KKU214 ${ }^{\mathrm{GemR}}$ cells. Our results highlight the therapeutic value of IVM: this drug could be used for treatment of CCA, especially in patients who do not respond to gemcitabine treatment.

\section{Conflicts of Interest}

The Authors have no conflicts of interest to declare regarding this study.

\section{Author's Contributions}

$\mathrm{KI}, \mathrm{CH}, \mathrm{PP}$, and SP designed the experiments. KI performed the experiments. KI, CH, PP, and SP performed the data analysis. KI and SP drafted the manuscript. All Authors approved the final version of manuscript for publication.

\section{Acknowledgements}

KI thanks the scholarship under the post-doctoral training program from research affairs and graduate school, Khon Kaen University, Thailand (Grant no. 60163) and also Khon Kaen University research fund (Grant no. KKU61004405). The Authors thank Prof. David Blair for critical reading and English editing of the manuscript.

\section{References}

1 Holohan C, Van Schaeybroeck S, Longley DB and Johnston PG: Cancer drug resistance: An evolving paradigm. Nat Rev Cancer 13(10): 714-726, 2013. PMID: 24060863. DOI: 10.1038/nrc3599

2 Housman G, Byler S, Heerboth S, Lapinska K, Longacre M, Snyder N and Sarkar S: Drug resistance in cancer: An overview. Cancers (Basel) 6(3): 1769-1792, 2014. PMID: 25198391. DOI: $10.3390 /$ cancers6031769

3 Khan SA, Davidson BR, Goldin R, Pereira SP, Rosenberg WM, Taylor-Robinson SD, Thillainayagam AV, Thomas HC, Thursz MR and Wasan H: Guidelines for the diagnosis and treatment of cholangiocarcinoma: Consensus document. Gut 51: VI1-9, 2002. PMID: 12376491. DOI: 10.1136/gut.51.suppl_6.vi1

4 Thongprasert S: The role of chemotherapy in cholangiocarcinoma. Ann Oncol 16: ii93-96, 2005. PMID: 15958484. DOI: $10.1093 /$ annonc/mdi712

5 Laing R, Gillan V and Devaney E: Ivermectin - old drug, new tricks? Trends Parasitol 33(6): 463-472, 2017. PMID: 28285851. DOI: $10.1016 /$ j.pt.2017.02.004

6 Norenberg W, Sobottka H, Hempel C, Plotz T, Fischer W, Schmalzing $\mathrm{G}$ and Schaefer M: Positive allosteric modulation by ivermectin of human but not murine $\mathrm{p} 2 \times 7$ receptors. Br J Pharmacol 167(1): 48-66, 2012. PMID: 22506590. DOI: 10.1111/j.1476-5381.2012.01987.x

7 Polakis P: Wnt signaling and cancer. Genes Dev 14(15): 18371851, 2000. PMID: 10921899.

8 Juarez M, Schcolnik-Cabrera A and Duenas-Gonzalez A: The multitargeted drug ivermectin: From an antiparasitic agent to a repositioned cancer drug. Am J Cancer Res 8(2): 317-331, 2018. PMID: 29511601.

9 Melotti A, Mas C, Kuciak M, Lorente-Trigos A, Borges I and Ruiz i Altaba A: The river blindness drug ivermectin and related macrocyclic lactones inhibit wnt-tcf pathway responses in human cancer. EMBO Mol Med 6(10): 1263-1278, 2014. PMID: 25143352. DOI: 10.15252/emmm.201404084

10 Liu Y, Fang S, Sun Q and Liu B: Anthelmintic drug ivermectin inhibits angiogenesis, growth and survival of glioblastoma through inducing mitochondrial dysfunction and oxidative stress. Biochem Biophys Res Commun 480(3): 415-421, 2016. PMID: 27771251. DOI: $10.1016 /$ j.bbrc.2016.10.064

11 Hashimoto $H$, Messerli SM, Sudo $T$ and Maruta $H$ : Ivermectin inactivates the kinase pak1 and blocks the pak1dependent growth of human ovarian cancer and nf2 tumor cell lines. Drug Discov Ther 3(6): 243-246, 2009. PMID: 22495656.

12 Sharmeen S, Skrtic M, Sukhai MA, Hurren R, Gronda M, Wang X, Fonseca SB, Sun H, Wood TE, Ward R, Minden MD, Batey RA, Datti A, Wrana J, Kelley SO and Schimmer AD: The antiparasitic agent ivermectin induces chloride-dependent membrane hyperpolarization and cell death in leukemia cells. Blood 116(18): 3593-3603, 2010. PMID: 20644115. DOI: 10.1182/blood-2010-01-262675

13 Jiang L, Wang P, Sun YJ and Wu YJ: Ivermectin reverses the drug resistance in cancer cells through egfr/erk/akt/nf-kappab pathway. J Exp Clin Cancer Res 38(1): 265, 2019. PMID: 31215501. DOI: 10.1186/s13046-019-1251-7

14 Pouliot JF, L'Heureux F, Liu Z, Prichard RK and Georges E: Reversal of p-glycoprotein-associated multidrug resistance by ivermectin. Biochem Pharmacol 53(1): 17-25, 1997. PMID: 8960059. DOI: 10.1016/s0006-2952(96)00656-9

15 Furusawa S, Shibata H, Nishimura H, Nemoto S, Takayanagi M, Takayanagi Y and Sasaki KI: Potentiation of doxorubicininduced apoptosis of resistant mouse leukaemia cells by ivermectin. Pharm Pharmacol Comm 6(3): 129-134, 2000. DOI: $10.1211 / 146080800128735764$

16 Tepsiri N, Chaturat L, Sripa B, Namwat W, Wongkham S, Bhudhisawasdi V and Tassaneeyakul W: Drug sensitivity and drug resistance profiles of human intrahepatic cholangiocarcinoma cell lines. World J Gastroenterol 11(18): 2748-2753, 2005. PMID: 15884115.

17 Wattanawongdon W, Hahnvajanawong C, Namwat N, Kanchanawat S, Boonmars T, Jearanaikoon P, Leelayuwat C, Techasen A and Seubwai W: Establishment and characterization of gemcitabine-resistant human cholangiocarcinoma cell lines with multidrug resistance and enhanced invasiveness. Int $\mathrm{J}$ Oncol 47(1): 398-410, 2015. PMID: 25998688. DOI: 10.3892/ ijo.2015.3019

18 Franken NA, Rodermond HM, Stap J, Haveman J and van Bree C: Clonogenic assay of cells in vitro. Nat Protoc 1(5): 23152319, 2006. PMID: 17406473. DOI: 10.1038/nprot.2006.339

19 Darzynkiewicz Z, Halicka HD and Zhao H: Analysis of cellular DNA content by flow and laser scanning cytometry. Adv Exp Med Biol 676: 137-147, 2010. PMID: 20687474. DOI: 10.1007/ 978-1-4419-6199-0_9

20 Leary M, Heerboth S, Lapinska K and Sarkar S: Sensitization of drug resistant cancer cells: A matter of combination therapy. Cancers (Basel) 10(12), 2018. PMID: 30518036. DOI: 10.3390/ cancers10120483

21 Gao Y, Shen JK, Milane L, Hornicek FJ, Amiji MM and Duan $\mathrm{Z}$ : Targeted cancer therapy; nanotechnology approaches for overcoming drug resistance. Curr Med Chem 22(11): 1335-1347, 2015. PMID: 25666804. 
22 Markman JL, Rekechenetskiy A, Holler E and Ljubimova JY: Nanomedicine therapeutic approaches to overcome cancer drug resistance. Adv Drug Deliv Rev 65(13-14): 1866-1879, 2013. PMID: 24120656. DOI: 10.1016/j.addr.2013.09.019

23 Al-Lazikani B, Banerji U and Workman P: Combinatorial drug therapy for cancer in the post-genomic era. Nat Biotechnol 30(7): 679-692, 2012. PMID: 22781697. DOI: 10.1038/nbt.2284

24 Omura S: Ivermectin: 25 years and still going strong. Int J Antimicrob Agents 31(2): 91-98, 2008. PMID: 18037274. DOI: 10.1016/j.ijantimicag.2007.08.023

25 Chen Q, Liu X, Luo Z, Wang S, Lin J, Xie Z, Li M, Li C, Cao $\mathrm{H}$, Huang Q, Mao J and Xu B: Chloride channel-3 mediates multidrug resistance of cancer by upregulating p-glycoprotein expression. J Cell Physiol 234(5): 6611-6623, 2019. PMID: 30230544. DOI: $10.1002 /$ jcp. 27402

26 Shimizu T, Lee EL, Ise T and Okada Y: Volume-sensitive cl(-) channel as a regulator of acquired cisplatin resistance. Anticancer Res 28(1A): 75-83, 2008. PMID: 18383827.

27 Kischel P, Girault A, Rodat-Despoix L, Chamlali M, Radoslavova S, Abou Daya H, Lefebvre T, Foulon A, Rybarczyk P, Hague F, Dhennin-Duthille I, Gautier M and OuadidAhidouch H: Ion channels: New actors playing in chemotherapeutic resistance. Cancers (Basel) 11(3), 2019. PMID: 30884858. DOI: $10.3390 /$ cancers 11030376
28 Varamo C, Peraldo-Neia C, Ostano P, Basirico M, Raggi C, Bernabei P, Venesio T, Berrino E, Aglietta M, Leone F and Cavalloni G: Establishment and characterization of a new intrahepatic cholangiocarcinoma cell line resistant to gemcitabine. Cancers (Basel) 11(4), 2019. PMID: 30979003. DOI: $10.3390 /$ cancers11040519

29 Zhu M, Li Y and Zhou Z: Antibiotic ivermectin preferentially targets renal cancer through inducing mitochondrial dysfunction and oxidative damage. Biochem Biophys Res Commun 492(3): 373-378, 2017. PMID: 28847725. DOI: 10.1016/j.bbrc.2017. 08.097
Received August 23, 2019

Revised August 28, 2019

Accepted August 30, 2019 